\title{
Oxidation mechanism of aluminum nitride revisited
}

\author{
Chun-Ting YEH, Wei-Hsing TUAN ${ }^{*}$ \\ Department of Materials Science and Engineering, "National Taiwan University", Taipei, Taiwan 106, China
}

Received: August 21, 2016; Revised: October 17, 2016; Accepted: October 29, 2016

(C) The Author(s) 2016. This article is published with open access at Springerlink.com

\begin{abstract}
Different from the oxidation kinetics of other nitrides, the oxide layer on AlN can easily reach tens of micrometers at a temperature above $1200{ }^{\circ} \mathrm{C}$. In the present study, the oxidation mechanism of AlN is investigated through microstructure observation. The analysis indicates that the oxide layer is full of small pores. The formation of pores generates additional surface area to induce further reaction. The reaction thus controls the oxidation in the temperature range from 1050 to $1350{ }^{\circ} \mathrm{C}$. The oxidation rate becomes slow as the oxide layer reaches a critical thickness.
\end{abstract}

Keywords: oxidation mechanism; aluminum nitride; diffusion; reaction

\section{Introduction}

Among nitrides, aluminum nitride (AIN) is unique for its high thermal conductivity [1]. With the increasing demand for the miniaturization of consumer electronics, AlN has come to be used as a carrier for electronic components [2]. Prior to the bonding of electronic components, a surface modification of the AlN substrate is usually needed $[3,4]$. This is usually accomplished by an oxidation treatment $[5,6]$. However, the treatment may degrade the thermal conductivity of AlN [3]. The oxidation behavior of AlN is therefore an important issue.

The mechanism for the oxidation of AlN has been examined in many studies [7-16]. Previous studies mainly measured weight gain during oxidation [7-11,13-16]. The weight increase after oxidation of AlN bulk at lower temperature is very small, which may result in uncertainty in the measurement. Some research groups thus have investigated the oxidation of AlN powder $[8,10,14,16]$. Weight gain is indeed larger for

\footnotetext{
* Corresponding author.
}

E-mail: tuan@ntu.edu.tw the powder; however, the oxidation starts at lower temperature and the corresponding activation energy is also lower (see Table 1).

Table 1 also lists the oxidation mechanisms proposed in these studies. The studies agree that the oxidation mechanism is either a reaction process or a diffusion process. The reaction process usually takes place at lower temperature. For AlN powder, the reaction process is found during oxidation in temperatures ranging from 550 to $1100{ }^{\circ} \mathrm{C}[8,10,14,16]$. For bulk specimens, the reaction process is found in the temperature interval from 1000 to $1390{ }^{\circ} \mathrm{C}[7,9,11-13$, 15]. Diffusion during oxidation is found in the temperature range from 950 to $1150{ }^{\circ} \mathrm{C}$ for AlN powder $[10,14]$, and from 900 to $1750{ }^{\circ} \mathrm{C}$ for bulk specimens $[7,11,13,15]$. Bellosi et al. [11] suggested that the diffusion is controlled by $\mathrm{O}^{2-}$ ions through the lattice or grain boundary.

While the previous studies agree upon the mechanism controlling oxidation, the reported values of activation energy show significant scatter from one study to another. For example, the activation energy varies from 67 to $366 \mathrm{~kJ} / \mathrm{mol}$ for the reaction process [11,16], and from 160 to $423 \mathrm{~kJ} / \mathrm{mol}$ for the diffusion 


\begin{tabular}{|c|c|c|c|c|c|}
\hline Reference & $\begin{array}{c}\text { Specimen } \\
+ \\
\text { additive }\end{array}$ & $\begin{array}{c}\text { Temperature } \\
\left({ }^{\circ} \mathrm{C}\right)\end{array}$ & Atmosphere & Kinetics & $\begin{array}{c}\text { Activation } \\
\text { energy } \\
(\mathrm{kJ} / \mathrm{mol})\end{array}$ \\
\hline $\begin{array}{l}\text { Lavrenko and } \\
\text { Alexeev [7] }\end{array}$ & Bulk & $900-1100$ & Oxygen & Parabolic & 255 \\
\hline $\begin{array}{l}\text { Katnani and } \\
\text { apathomas [8] }\end{array}$ & Powder & $700-900$ & Air & Linear & 151 \\
\hline Sato et al. [9] & Bulk & $1150-1250$ & $\begin{array}{c}\text { Wet } \\
\text { nitrogen }\end{array}$ & Linear & 250 \\
\hline \multirow{2}{*}{$\begin{array}{l}\text { uryanarayana } \\
{[10]}\end{array}$} & Powder & $800-1100$ & Air & Linear & 188 \\
\hline & Powder & $950-1100$ & Air & Parabolic & 297 \\
\hline \multirow{4}{*}{$\begin{array}{c}\text { Bellosi et al. } \\
\text { [11] }\end{array}$} & Bulk & $1100-1390$ & Air & Linear & 260 \\
\hline & $\begin{array}{c}\text { Bulk+ } \\
\mathrm{Y}_{2} \mathrm{O}_{3}\end{array}$ & $1100-1250$ & Air & Linear & 366 \\
\hline & $\begin{array}{l}\text { Bulk+ } \\
\mathrm{CaC}_{2}\end{array}$ & $1100-1200$ & Air & Linear & 366 \\
\hline & $\begin{array}{l}\text { Bulk }+ \\
\mathrm{CaC}_{2} \\
\end{array}$ & $>1250$ & Air & Parabolic & 160 \\
\hline $\begin{array}{l}\text { Robinson and } \\
\text { Dieckmann } \\
\text { [12] }\end{array}$ & Bulk & $1000-1300$ & Air & Linear & 347 \\
\hline Osborne and & Bulk & $1150-1350$ & Air & Linear & 175 \\
\hline Norton [13] & Bulk & $1350-1750$ & Air & Parabolic & 395 \\
\hline Brown and & Powder & $850-950$ & Air & Linear & 271 \\
\hline Norton [14] & Powder & $950-1150$ & Air & Parabolic & 423 \\
\hline $\begin{array}{c}\text { Tseng et al. } \\
{[15]}\end{array}$ & Bulk & $1150-1450$ & Air & Parabolic & 369 \\
\hline $\begin{array}{c}\text { Zhou et al. } \\
{[16]}\end{array}$ & $\begin{array}{l}\text { Powder+ } \\
\text { fluorides }\end{array}$ & $550-700$ & Air & Linear & 67 \\
\hline This study & $\begin{array}{c}\text { Bulk+ } \\
\mathrm{Y}_{2} \mathrm{O}_{3}\end{array}$ & $1050-1350$ & Air & Linear & 187 \\
\hline
\end{tabular}

process [11-14]. Bellosi et al. [11] demonstrated that the activation energy of reaction increases from 260 to $366 \mathrm{~kJ} / \mathrm{mol}$ after the addition of $3 \mathrm{wt} \% \mathrm{Y}_{2} \mathrm{O}_{3}$. The variation of the reported values of activation energy is thus related to composition effects. Nevertheless, the activation energies for the systems of $\mathrm{AlN}-3 \% \mathrm{Y}_{2} \mathrm{O}_{3}$ and AlN $-2 \% \mathrm{CaC}_{2}$ are exactly the same when their oxidation is controlled by reaction (Table 1). To be demonstrated later, the oxidation kinetics of AlN is relatively fast, which has never been addressed before. In order to investigate the oxidation mechanism, detailed microstructure analysis is conducted in the present study.

\section{Experimental}

AlN (AN-170, 2 wt $\% \mathrm{Y}_{2} \mathrm{O}_{3}$, Maruwa Co., Aichi, Japan) substrates with a thickness of $0.38 \mathrm{~mm}$ and a surface roughness $\left(R_{\mathrm{a}}\right)$ of $0.34 \mu \mathrm{m}$ were used in the present study. The specimens were cleaned first in an ultrasonic bath of ethyl alcohol, then in one of acetone. Prior to the oxidation treatments, the substrate was heat treated at
$500{ }^{\circ} \mathrm{C}$ for $4 \mathrm{~h}$ in air. This temperature was high enough to remove any organics, and low enough to induce noticeable oxidation $[7,8,11,16]$. The oxidation was carried out in a tube furnace. The AlN substrate was oxidized within alumina crucible. The purity of alumina crucible was higher than $99 \% \mathrm{Al}_{2} \mathrm{O}_{3}$ to avoid the contamination. The oxidation was conducted at 1050 , $1150,1250,1350$, and $1450{ }^{\circ} \mathrm{C}$ for 1,2 , and $4 \mathrm{~h}$ in flowing air. The humidity in air was $3 \mathrm{ppm}$, as reported by the provider (Air Products Inc., Taipei, Taiwan, China).

To determine the extent of oxidation, the thickness of the surface oxide layer was estimated with electron probe micro-analysis (EPMA; JXA-8200, JEOL Co., Tokyo, Japan). Since the oxidation of AIN results from the reaction and diffusion of oxygen, the distribution of oxygen within the specimen was used as the evidence of oxidation. The EPMA technique can locate oxygen near the surface, and the thickness of the oxide layer was then estimated from maps of oxygen ions. The resolution of the technique was around $1 \mu \mathrm{m}$. A high-resolution transmission electron microscope (TEM; FEI Tecnai G $^{2}$ F20, Philips Co., Oregon, USA) was also used to characterize the microstructure. The TEM foil was prepared using an environmental dual-beam focused-ion-beam system (FIB; FEI Helios 600i, Philips Co., Oregon, USA). The phase analysis was conducted using X-ray diffraction (XRD; TTRAX-III, Rigaku Co., Tokyo, Japan).

\section{Results}

Figure 1 shows SEM back-scattered micrographs for the surface region of the oxidized substrates. Some white particles are found within the specimens. These particles are composed of $\mathrm{Y}, \mathrm{Al}$, and $\mathrm{O}$ as determined by EPMA. Figure 2 shows the XRD patterns of the specimens oxidized at various temperatures for $4 \mathrm{~h}$. Only AIN (major) and YAG $\left(3 \mathrm{Y}_{2} \mathrm{O}_{3} \cdot 5 \mathrm{Al}_{2} \mathrm{O}_{3}\right.$, minor) are detected for the starting AlN substrate. According to the producer of the AlN substrate, the $\mathrm{Y}_{2} \mathrm{O}_{3}$ additive would react with the oxide layer on AlN particles to form YAG during hot-pressing. Since the amount of $\mathrm{Y}_{2} \mathrm{O}_{3}$ was low, $2 \mathrm{wt} \%$, the amount of YAG is also low.

The $\alpha-\mathrm{Al}_{2} \mathrm{O}_{3}$ phase is found after oxidation at $1050{ }^{\circ} \mathrm{C}$ for $4 \mathrm{~h}$. The amount of $\mathrm{Al}_{2} \mathrm{O}_{3}$ increases with increasing oxidation temperature. From the width of the XRD peaks, the size of $\mathrm{Al}_{2} \mathrm{O}_{3}$ grains within the oxide 


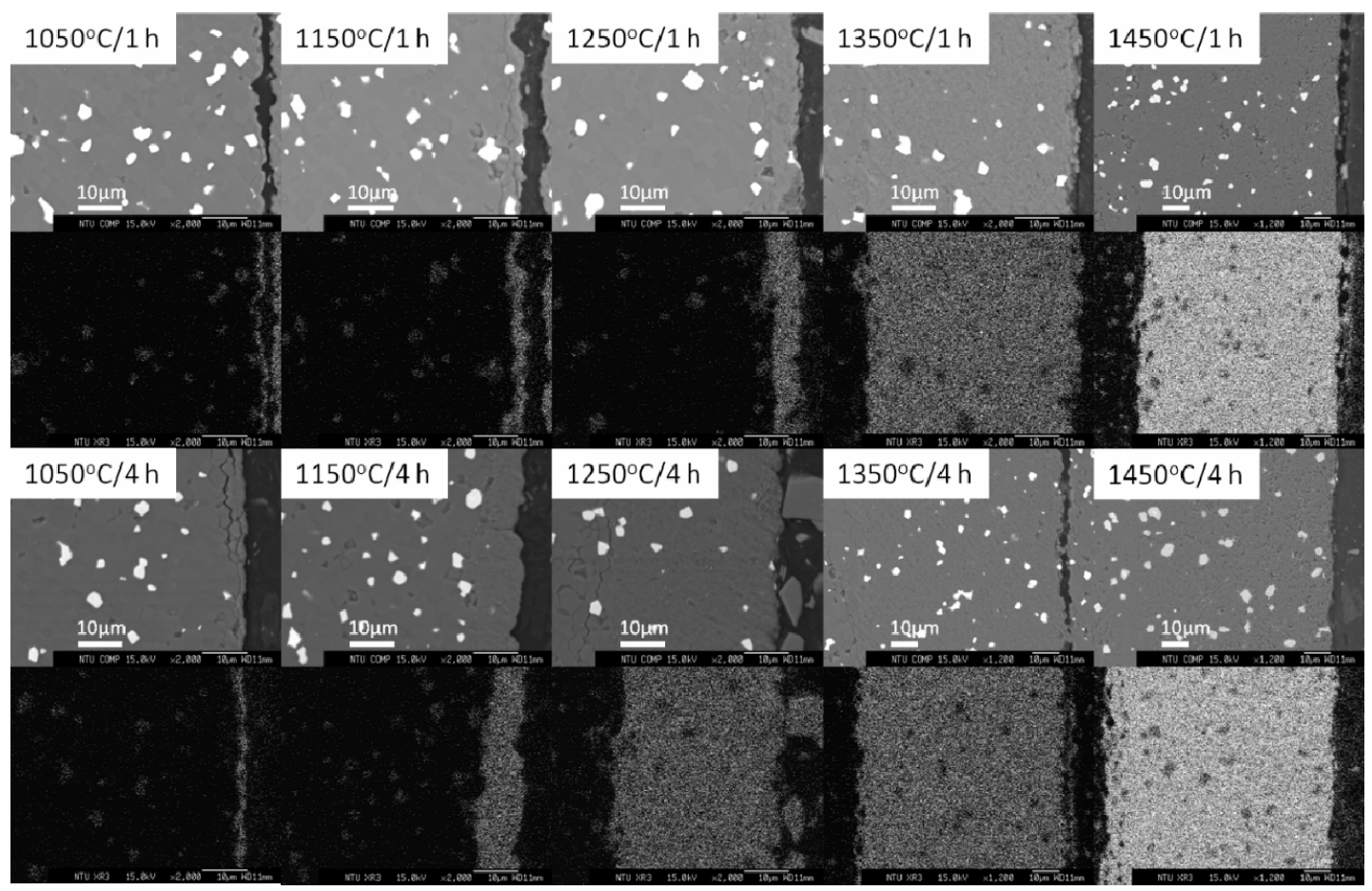

Fig. 1 SEM back-scattered micrographs for the surface region of oxidized AlN specimens and their corresponding maps of oxygen. Note that the magnification for micrographs of the specimens oxidized at $1350{ }^{\circ} \mathrm{C} / 4 \mathrm{~h}, 1450{ }^{\circ} \mathrm{C} / 1 \mathrm{~h}$, and $1450{ }^{\circ} \mathrm{C} / 4 \mathrm{~h}$ is lower.

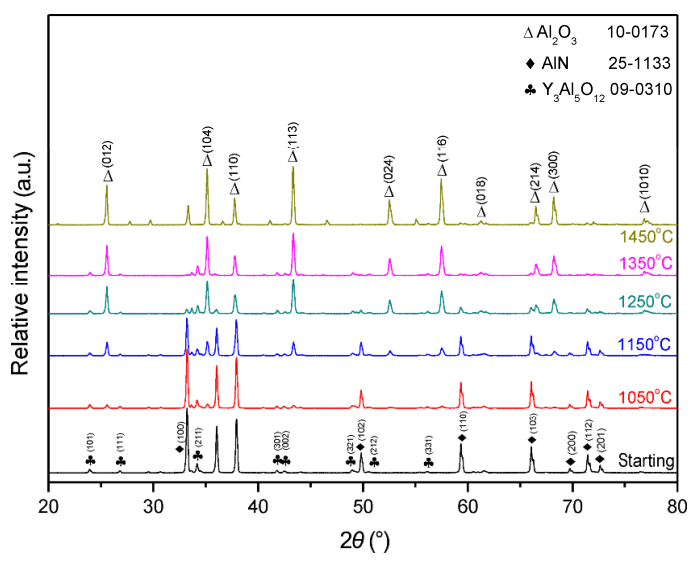

Fig. 2 XRD patterns for AIN specimens oxidized at various temperatures for $4 \mathrm{~h}$.

layer is around $40 \mathrm{~nm}$ for the substrate oxidized at $1050{ }^{\circ} \mathrm{C}$ and around $50 \mathrm{~nm}$ for the substrate oxidized at $1450{ }^{\circ} \mathrm{C}$.

Figure 3(a) shows a TEM micrograph of the AlN phase located within the substrate. Figure 3(b) shows a micrograph of the oxide layer. There are many pores within the oxide layer; the size of these pores is around $50 \mathrm{~nm}$ in length and around $20 \mathrm{~nm}$ in width. The long axis of the pores tends to be perpendicular to the surface of the substrate.

Figure 1 shows the mapping of the oxygen in the surface region. By assuming that the layer with oxygen is the oxidation product, the extent of oxidation can be estimated. More than three locations for each oxide layer were measured; the average and its standard deviation are shown in Fig. 4. The oxide layer is thin when the oxidation is conducted at 1050 and $1150{ }^{\circ} \mathrm{C}$. The layer increases its thickness rapidly as the oxidation temperature exceeds $1250{ }^{\circ} \mathrm{C}$. However, the thickness of oxide layer reaches its plateau after oxidization at $1450{ }^{\circ} \mathrm{C}$ for $2 \mathrm{~h}$.

\section{Discussion}

In the present study, the oxidation behavior of AlN substrates in the temperature interval from 1050 to $1450{ }^{\circ} \mathrm{C}$ is investigated. The oxidation is controlled by either reaction or diffusion. The reaction process involves the formation of nitrogen as shown in the equation below $[9,17]$ :

$$
2 \mathrm{AlN}+\frac{3}{2} \mathrm{O}_{2} \rightarrow \mathrm{Al}_{2} \mathrm{O}_{3}+\mathrm{N}_{2}
$$

Due to the change from AlN to $\mathrm{Al}_{2} \mathrm{O}_{3}$, the above reaction is associated with a weight gain of $24 \%$. The oxidation of AlN can therefore be monitored through the measurement of weight gain.

In contrast to the previous studies [7-16], the extent 


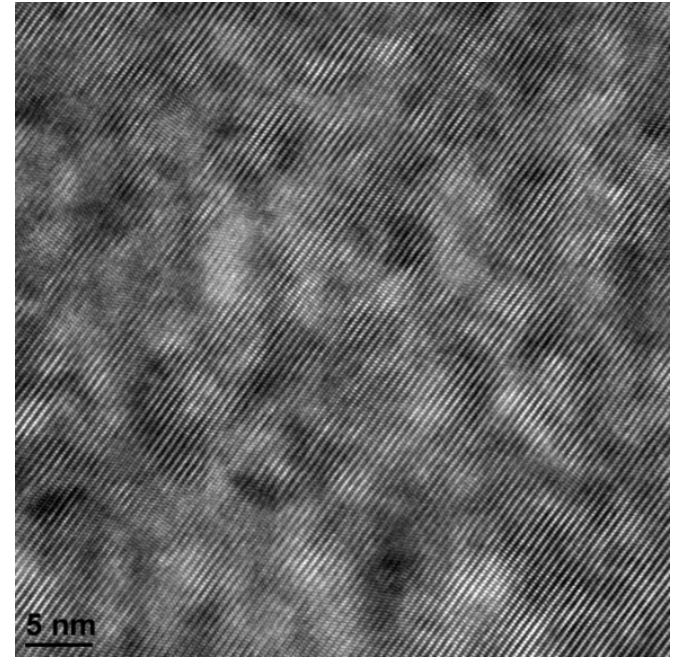

(a)

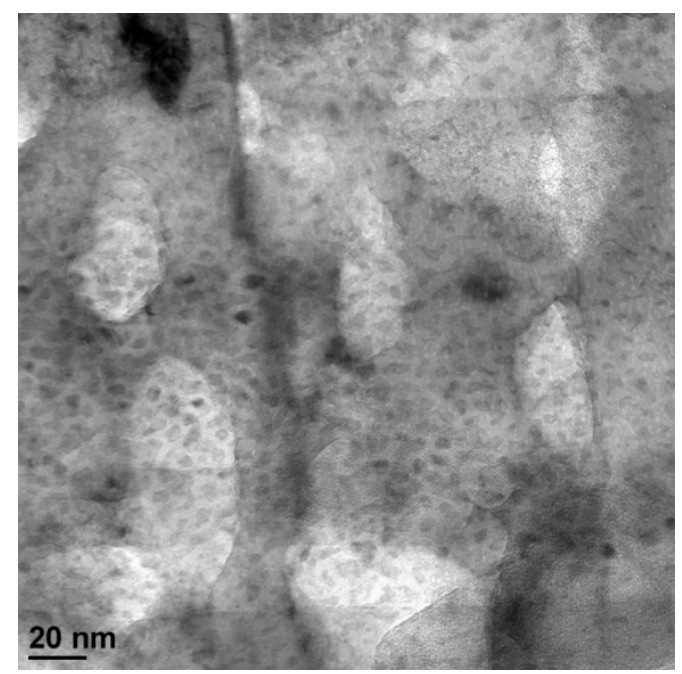

(b)

Fig. 3 TEM micrographs for (a) AlN specimen and (b) oxide layer after oxidation at $1150{ }^{\circ} \mathrm{C}$ for $1 \mathrm{~h}$.

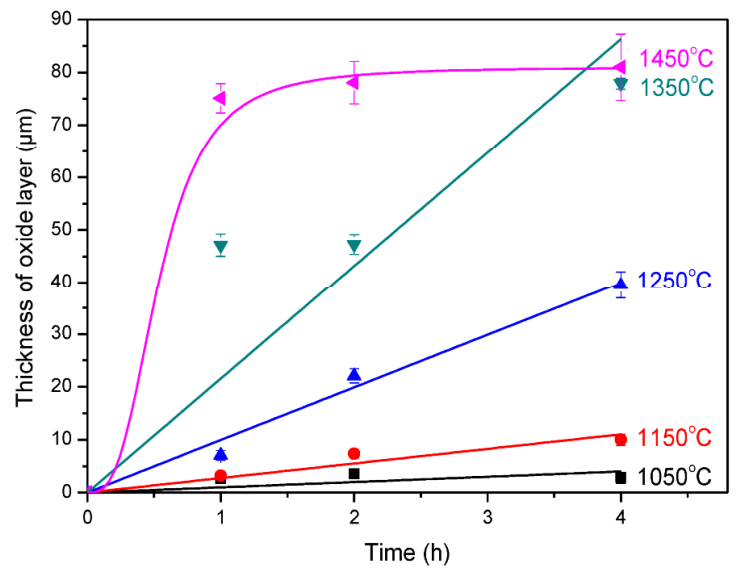

Fig. 4 Thickness of the oxide layer as a function of oxidation time at various temperatures. The thickness was estimated from the oxygen maps shown in Fig. 1. of oxidation is determined through the measurement of the thickness of oxide layer (Fig. 4). The details of the microstructure of the oxide layer are revealed through the TEM analysis. Many pores are found within the oxide layer (Fig. 3(b)). Though the presence of pores within the oxide layer of AIN specimens was also observed in previous studies [9], their formation had been related to the presence of water in the oxidation environment as demonstrated by the following reaction [9]:

$$
2 \mathrm{AlN}+3 \mathrm{H}_{2} \mathrm{O} \rightarrow \mathrm{Al}_{2} \mathrm{O}_{3}+\mathrm{N}_{2}+3 \mathrm{H}_{2}
$$

However, the Gibbs free energy for reaction (1) is lower than that for reaction (2) in the temperature interval investigated [17]. Furthermore, the water content, or humidity level, in the oxidation environment of the present study is very low. The oxidation is likely controlled by reaction (1). In any case, the reactions (1) and (2) involve the formation of nitrogen.

The presence of pores confirms that the reaction is indeed taken place during oxidation. The reaction during oxidation forms a thick oxide layer.

Many nitrides are resistant to oxidation at elevated temperatures. For example, the thickness of oxide layer for a reaction-bonded silicon nitride (RBSN) is only $3 \mu \mathrm{m}$ after oxidation at $1400{ }^{\circ} \mathrm{C}$ for $50 \mathrm{~h}$ [18]. Nevertheless, the thickness of the oxide layer on AIN reaches $45 \mu \mathrm{m}$ after oxidation at $1350{ }^{\circ} \mathrm{C}$ for only $1 \mathrm{~h}$.

The diffusion coefficients of $\mathrm{Al}^{3+}$ and $\mathrm{O}^{2-}$ ions through the lattice and grain boundary in aluminum oxide are well documented [19,20]. The following equations show one set of relationships for the diffusion coefficient of $\mathrm{Al}^{3+}$ ions through the lattice $\left(D_{1}\right)$ and through the grain boundary $\left(D_{\mathrm{gb}}\right)[19]$ :

$$
\begin{aligned}
& D_{1}=1.36 \times 10^{5} \exp \left(-\frac{577 \mathrm{~kJ} / \mathrm{mol}}{R T}\right) \\
& \delta D_{\mathrm{gb}}=8.6 \times 10^{-4} \exp \left(-\frac{418 \mathrm{~kJ} / \mathrm{mol}}{R T}\right)
\end{aligned}
$$

In the above equations, $\delta$ is the thickness of the grain boundary, $R$ the Boltzmann constant, and $T$ the absolute temperature. Other reported values for the lattice diffusion coefficient $\left(D_{1}\right)$ vary from $10^{-15}$ to $10^{-11} \mathrm{~cm}^{2} / \mathrm{s}$ in the temperature range from 1100 to $1500{ }^{\circ} \mathrm{C}$, the boundary diffusivity $\left(\delta D_{\mathrm{gb}}\right.$ ) from $10^{-18}$ to $10^{-14} \mathrm{~cm}^{2} / \mathrm{s}$ $[19,20]$. These values are very low, which suggests that no matter whether the diffusion is through the lattice or through the grain boundary, the diffusion distance should be on the order of $1 \mu \mathrm{m}$ in the temperature range from 1000 to $1500{ }^{\circ} \mathrm{C}$. Nevertheless, the thickness of 
the oxide layer reaches a value of $75 \mu \mathrm{m}$ after oxidation at $1450{ }^{\circ} \mathrm{C}$ for $1 \mathrm{~h}$ (Fig. 4). Also note that there is a limit for the thickness of the oxide layer. For example, after the oxidation is conducted at $1450{ }^{\circ} \mathrm{C}$ for $1 \mathrm{~h}$, the thickness of the oxide layer increases to $75 \mu \mathrm{m}$. It takes 3 more hours to increase from 75 to $81 \mu \mathrm{m}$.

The key to the oxidation of AlN is that the oxide layer is porous (Fig. 3(b)). The oxidation of AlN is accompanied by the formation of nitrogen as shown in reaction (1). The formation of small pores generates considerable fresh surface area to allow further reaction to take place. The oxide layer is therefore thick. However, the reaction is possible only when the exchange of nitrogen and oxygen is possible. In other words, the pore channel must allow the transportation of the gases. Figure 4 indicates that there is a maximum thickness for the oxide layer. This implies that the pore channels may be no longer available as the oxide layer is too thick. As the pores are not interconnected, only the diffusion of oxygen ions within the oxide layer is possible. The thickness increases slowly at elevated temperatures, mainly because the diffusion coefficient of ions in $\mathrm{Al}_{2} \mathrm{O}_{3}$ is small. From Fig. 4, the critical layer thickness is around $80 \mu \mathrm{m}$. To achieve such a thickness, oxidation at $1350{ }^{\circ} \mathrm{C}$ for $4 \mathrm{~h}$ or $1450{ }^{\circ} \mathrm{C}$ for $1 \mathrm{~h}$ is needed. Since the oxidation within the temperature range from 1050 to $1350{ }^{\circ} \mathrm{C}$ is a reaction process, it is possible to calculate its activation energy. The value for the activation energy is $187 \mathrm{~kJ} / \mathrm{mol}$. Our value falls within the range reported from the previous studies (67$366 \mathrm{~kJ} / \mathrm{mol}$ in Table 1).

A schematic for the oxidation of AlN is shown in Fig. 5. The schematic illustrates the reaction involving the exchange of oxygen and nitrogen. Many small pores are produced by this reaction. The long axis of the pores thus tends to be perpendicular to the surface. The reaction process generates fresh surface area, facilitating further reaction. The increase in thickness of the oxide layer is therefore rapid. Diffusion may take place simultaneously within the thin oxide layer around each pore. However, the diffusion of aluminum and oxygen ions within aluminum oxide is so slow that the diffusion process contributes little to the thickness increase of the oxide layer.

\section{Conclusions}

With the help of microstructure analysis, the oxidation

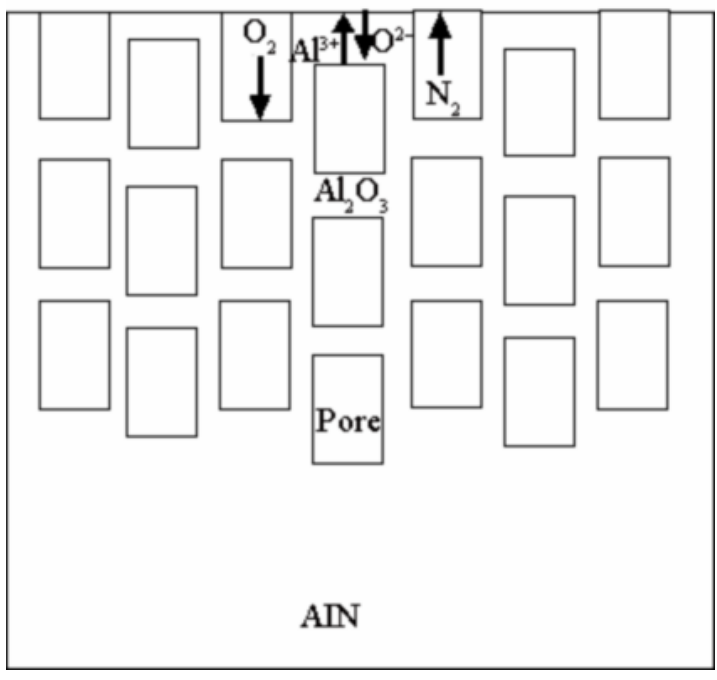

Fig. 5 Schematic showing the formation of the oxide layer during the oxidation of AlN. The oxidation process is mainly the reaction involving the exchange of $\mathrm{N}_{2}$ and $\mathrm{O}_{2}$.

mechanism of AlN is investigated in the present study. The oxide layer formed on the surface of AlN substrate is a porous one. The oxidation kinetics is therefore fast. The reaction induces a rapid increase in weight and in oxide thickness, due to the formation of many pores. The reaction stops when the pores are no longer interconnected.

\section{Acknowledgements}

The present study was supported by the "Ministry of Science and Technology" through the Contract No. NSC100-3113-E-002-001.

\section{References}

[1] Yoshimura HN, Narita NE, Molisani AL, et al. High temperature flexural strength and fracture toughness of AlN with $\mathrm{Y}_{2} \mathrm{O}_{3}$ ceramic. J Mater Sci 2009, 44: 5773-5780.

[2] Kar JP, Bose G, Tuli S, et al. Morphological investigation of aluminium nitride films on various substrates for MEMS applications. Surf Eng 2009, 25: 526-530.

[3] Yeh C-T, Tuan W-H. Pre-oxidation of AlN substrates for subsequent metallization. J Mater Sci: Mater El 2015, 26: 5910-5916.

[4] Iwase N, Anzai K, Shinozaki K, et al. Thick film and direct bond copper forming technologies for aluminum nitride substrate. IEEE T Compon Hybr 1985, 8: 253-258.

[5] Chiang WL, Greenhut VA, Shanefield DJ, et al. Effect of substrate and pretreatment on copper to AIN direct bonds. In Proceedings of the 15th Annual Conference on Composites and Advanced Ceramic Materials, Part 2 of 2: Ceramic Engineering and Science Proceedings, 1991, 12, DOI: $10.1002 / 9780470313848 . \operatorname{ch} 38$. 
[6] Watanabe Y, Hara Y, Tokuda T, et al. Surface oxidation of alumiuium nitride thin films. Surf Eng 2000, 16: 211-214.

[7] Lavrenko VA, Alexeev AF. Oxidation of sintered aluminium nitride. Ceram Int 1983, 9: 80-82.

[8] Katnani AD, Papathomas KI. Kinetics and initial stages of oxidation of aluminum nitride: Thermogravimetric analysis and X-ray photoelectron spectroscopy study. $J$ Vac Sci Technol A 1987, 5: 1335-1340.

[9] Sato T, Haryu K, Endo T, et al. High temperature oxidation of hot-pressed aluminium nitride by water vapour. $J$ Mater Sci 1987, 22: 2277-2280.

[10] Suryanarayana D. Oxidation kinetics of aluminum nitride. J Am Ceram Soc 1990, 73: 1108-1110.

[11] Bellosi A, Landi E, Tampieri A. Oxidation behavior of aluminum nitride. J Mater Res 1993, 8: 565-572.

[12] Robinson D, Dieckmann R. Oxidation of aluminium nitride substrates. J Mater Sci 1994, 29: 1949-1957.

[13] Osborne EW, Norton MG. Oxidation of aluminium nitride. J Mater Sci 1998, 33: 3859-3865.

[14] Brown AL, Norton MG. Oxidation kinetics of AIN powder. J Mater Sci Lett 1998, 17: 1519-1522.

[15] Tseng WJ, Tsai C-J, Fu S-L. Oxidation, microstructure and metallization of aluminum nitride substrates. J Mater Sci: Mater El 2000, 11: 131-138.
[16] Zhou H, Qiao L, Fu R. Effect of the fluoride additives on the oxidation of AlN. Mater Res Bull 2002, 37: 2427-2435.

[17] Stull DR, Prophet H. JANAF Thermochemical Tables, 2nd edn. National Bureau of Standards US, 1971.

[18] Haggerty JS, Lightfoot A, Ritter JE, et al. Oxidation and fracture strength of high-purity reaction-bonded silicon nitride. J Am Ceram Soc 1989, 72: 1675-1679.

[19] Cannon RM, Rhodes WH, Heuer AH. Plastic deformation of fine-grained alumina $\left(\mathrm{Al}_{2} \mathrm{O}_{3}\right)$ : I, interface-controlled diffusional creep. J Am Ceram Soc 1980, 63: 46-53.

[20] Nakagawa T, Nishimura H, Sakaguchi I, et al. Grain boundary character dependence of oxygen grain boundary diffusion in $\alpha-\mathrm{Al}_{2} \mathrm{O}_{3}$ bicrystals. Scripta Mater 2011, 65: $544-547$.

Open Access The articles published in this journal are distributed under the terms of the Creative Commons Attribution 4.0 International License (http://creativecommons. org/licenses/by/4.0/), which permits unrestricted use, distribution, and reproduction in any medium, provided you give appropriate credit to the original author(s) and the source, provide a link to the Creative Commons license, and indicate if changes were made. 